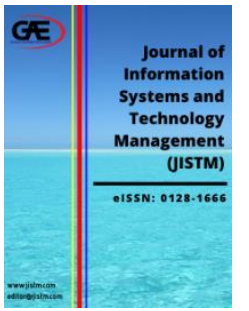

\author{
JOURNAL OF INFORMATION \\ SYSTEM AND TECHNOLOGY \\ MANAGEMENT (JISTM) \\ WWW.jistm.com
}

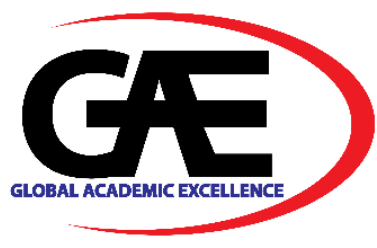

\title{
INTERNET CELEBRITIES: HOW THEY AFFECT THE PURCHASE INTENTION OF GENERATION Y IN CYBERSPACE?
}

\author{
Ying San Lim ${ }^{1 *}$, Tuan Hock $\mathrm{Ng}^{2}$, Yi Shin $\mathrm{Hng}^{3}$ \\ 1 Faculty of Business, Multimedia University, Melaka, Malaysia \\ Email: lim.ying.san@mmu.edu.my \\ 2 Faculty of Business, Multimedia University, Melaka, Malaysia \\ 3 Faculty of Business, Multimedia University, Melaka, Malaysia \\ Corresponding Author
}

\section{Article Info:}

\section{Article history:}

Received date: 13.07 .2020

Revised date: 10.08 .2020

Accepted date: 30.09 .2020

Published date: 01.12.2020

\section{To cite this document:}

Lim, Y. S., Ng, T. H., \& Hng, Y. S. (2020). Internet Celebrities: How They Affect the Purchase Intention of Generation Y in Cyberspace? Journal of Information System and Technology Management, 5 (19), 5159.

DOI: $10.35631 /$ JISTM.519005.

This work is licensed under CC BY 4.0

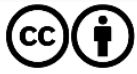

\begin{abstract}
:
The use of social media had created a group of ordinary people who actively share their life and experiences on the social media platform. When this group of people received more and more "likes" from the audiences, they are being named as Internet celebrities. Internet celebrities who are having many followers had created the opportunity for the businesspeople to engage them in promoting and selling the products. However, despite the growth of social media and the use of social media by businesspeople, there are not many studies on internet celebrities that affecting the purchase intention among the customers in Malaysia. Hence, the problem statement of this study is to investigate the characteristic affecting internet celebrities that will affect the purchase intention of the consumers. The research had been done by collecting feedback from 200 respondents from Generation Y. An online questionnaire with 5-Likert rating scales is used to collect the data. Convenient sampling techniques were used to collect the data. The result of the study indicated that source credibility and video characteristic are the most important factors in influencing purchase intention, however, physical attractiveness and interactivity are not going to influence purchase intention. This gives an insightful thought to marketers to request internet celebrities to produce more quality videos to attract viewer attention. In terms of source credibility, marketers need to find Internet celebrities who have a more credible image to sell the company products. The justifications for the rejected hypotheses were discussed in detail in the study. The research findings of this study give marketers and academics insightful thoughts on how Internet celebrities can influence the purchase intention of Generation Y today.
\end{abstract}


Keywords:

Interactivity, Physical Attractiveness, Source Credibility, Video Characteristics

\section{Introduction}

Social media is a platform that allows users to communicate and to share information online. With the advance in Internet technology, social media such as Facebook, Instagram, Twitter, YouTube had been integrated into our life. Social media nowadays is not only served as a platform to share or to communicate information, however, today, social media also served as a platform for businesspeople to reach and disseminate the information to their customers. In the United States, the use of social media was grown exponentially, according to the study, the penetration rate for the social media is $79 \%$ which is equivalence to 246.7 Million User (Clement, 2019).

Internet celebrities are creators of social media content, they normally post the video on their channel to gain subscribers. Internet celebrities can also be defined as an influencer who promote product or brand through any form of social media (Veirman, 2017). The most popular type of internet celebrities in social media platforms is YouTuber (Djafarova \& Rushworth, 2017; Sokolova \& Kefi, 2019). However, there is also a rise of live stream influencers which is very popular in some countries like China and Taiwan (Cai and Wohn, 2019; Chang and Woo, 2019). Things turn to be more interesting when some Internet Celebrities are actively involved in themself in product selling.

One of the factors that contributed to the rise of internet celebrity phenomena is the shift from traditional media to new media especially among Generation Y and Z (McKay, 2018). According to Poggi (2018) half of the Generation Y do not watch any traditional television at all. One of the surveys conducted among the teenagers in the United States indicated that YouTubers are more influential celebrities compared to the traditional celebrities among the Generation $\mathrm{Y}$ and Z.

Besides, according to Gutella (2015), Generation Y is more willing to try the new brand and new product endorsed by internet celebrities compared to traditional celebrities. Also, the research mentioned that, six-in-ten Generation Y will make their purchase decision based on the recommendation of the YouTuber (Arnold, 2017). All these phenomena showed that internet celebrities are the one who plays an important role in connecting the brand to customers in today's market.

In Malaysia, the same phenomena happened. According to Kaur (2016), Malaysian are quite attached to social media. Malaysians used different types of social media sites. Among all the different sites, Facebook is the most popular platform with $97.3 \%$ of Malaysian owned Facebook account followed by Instagram, which is 56.1\%. (MCMC Internet Survey, 2017). Besides, according to Facebook, there are $94 \%$ of Malaysians discover products and brands on Facebook and $62 \%$ of them purchase the discovery (Soyacincau, 2016). The attachment of Malaysian towards social media no doubts had created a new business opportunity for businesspeople to communicate and to sell their products. 


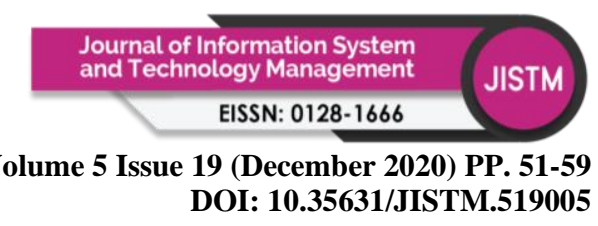

As internet celebrities are getting more and more popular today, there are some researchers started to study internet celebrities (Konzack, 2019; Park \& Lin, 2020). However, despite the growth of social media and the use of social media by the businesspeople, to the researcher's knowledge, up to date, there are not many studies on the internet celebrities that affecting the purchase intention among the customers being conducted in Malaysia. Hence, the problem statement of this study is to investigate the characteristic that affecting internet celebrities which might affect the purchase intention of the consumers.

The main objectives of the study are to identify the digital celebrity characteristics: source credibility, physical attractiveness, video characteristic, and interactivity on its influence of purchase intention among Generation $\mathrm{Y}$ in Malaysia. The study is important as it can help the marketer to understand the Internet celebrity trend and to develop better marketing strategies and to use the right marketing channel to target their customers. Also, for the academic's perspective, the study can enrich online study by discussing the influence of Internet celebrities among Malaysia Generation Y customers.

\section{Literature Review}

Purchase Intention is defined as consumers' intention to purchase a product and service in the future (Hsu \& Tsou, 2011). Purchase intention usually related to the consumer's attitude and preferences.

According to a study from Mir and Rehman (2013), social media especially Youtube is an important application for the business to advertise their product and service. YouTube has a positive effect on consumer purchase intention because there are many users especially the new generation heavily dependent on YouTube rather than traditional media such as TV, radio, newspaper, magazine (Westenberg, 2016). In addition, a previous study showed that consumer intention to purchase a certain product or service increased after watching the YouTube video (Yuksel, 2016).

Looking at the unique cyberspace environment, this study explored the psychical characteristic of the Internet celebrity and also the tools used in cyberspace when they are promoting themself and the products. Those tools include video characteristics and also the interactivity of Internet celebrities and their viewer.

Source credibility is defined as a situation where the message believable depends on the credit status of a person perceived in the consumer mind (Umeogu, 2012). Studies found that sources from social media is more credibility comparing with traditional media (Shareef, 2019). According to Yoon, Kim, \& Kim (1998), source credibility and trustworthiness were important to predict purchase intention and affect an attitude toward advertising of a product and service.

Hence, the $\mathrm{H} 1$ of this study is:

H1: There is a significant relationship between source credibility and purchase intention.

Physical Attractiveness is defined as the physical appearance and perceived personality of the source. (Sallam, 2011). The attractiveness of celebrities able to capture consumer attention and influence purchase intention toward a certain product or service (Ohanian, 1991). Moreover, the previous study related to marketing advertising perspective, physical attractive gain positive result on the consumer in most of the time (Kahle and Homer ,1985). Additionally, 
according to Joseph (1982), face cues were not the most important element of a person's physical attractiveness, but it is the most influential dimension of a person's physical attractiveness. Study by Albert (1972) also showed that $7 \%$ and $38 \%$ out of $100 \%$ of the total impact was verbal and vocal. 55\% of the total impact was influenced by facial cues. This result also supports that physical attractiveness will gain consumer attention while communicating or delivering a message. Hence, the $\mathrm{H} 2$ of this study is:

$\mathrm{H} 2$ : There is a significant relationship between physical attractiveness and purchase intention.

Interactivity is known as the interaction between a person with another person, In a unique cyberspace environment enables the viewer and the Internet celebrities to communicate and to get instant feedback from the viewer (Glucksman, 2017). Previous studies showed, in the Internet celebrities' social media, their fans will trust and get influenced by the celebrities when they are exposed to the celebrities. This is because the repeated exposure of the video can elicit feeling of relationship enhancement. If this relationship continues develop, the viewer will start to seek the Internet celebrity's advice and develop their trust on the them (Lee \& Watkins, 2016; Rubin Perse \& Powell,1985). Hence, the H3 of this study is:

H3: There is a significant relationship between interactivity and purchase intention.

Video characteristic is defined as the features of the video which include the speaking style, aesthetic, and quality and the length of the video (Yuksel, 2016; Westenberg, 2016). The research conducted by Yuksel (2016) stated that a good YouTuber able to influences the audience's purchase intention. Also, video aesthetic can make the video looks more interesting, also, the video which have better technical edition also will make viewer willing to spend more time to see their video. Hence, the $\mathrm{H} 4$ of this study is:

$\mathrm{H} 4$ : There is a relationship association between video characteristics and purchase intention.

The research framework is showed in Figure 1 below:

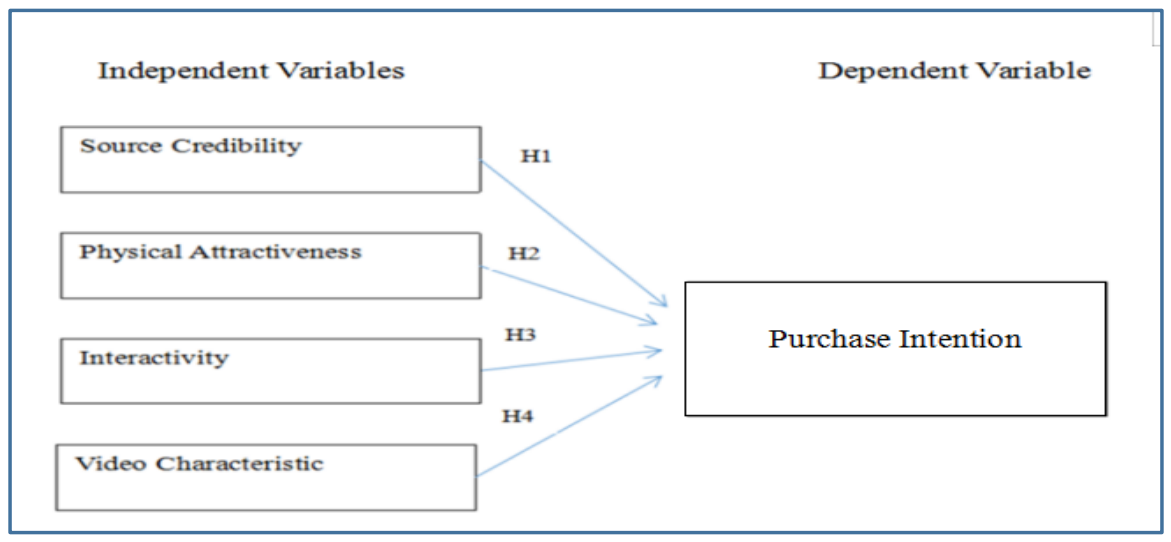

Figure 1: Research Framework

\section{Methodology}

The research had been done by collecting the feedback from 200 respondents from Generation $\mathrm{Y}$ by using a questionnaire. Generation $\mathrm{Y}$ is selected in this study as this cohort is the group who more attached to the Internet and social media (MCMC Internet Survey, 2017). Generation Y can be known as Echo Boomers, Millennial. There were different journals and countries to study the age of Generation Y. According to Howe and Strauss (2000) gen Y was born between 
the age of 1982 to 2000 which between the ages 37 to 19 . However, in understanding consumer concept they present that Generation Y was born between 1980 to 1996 and there were 23 to 39 (Schiffman and Wisenblit, 2019). Therefore, in this study, the study focuses on generation Y between the ages of 19 to 39 years old.

Nonprobability convenience sampling was used to distribute the online questionnaire to the targeted respondents. Screening questions were added in the questionnaire to identify the suitability of the respondents in participating in the study. The online questionnaire with 5Likert rating scales is used to collect the data. All the measurement scale used in the questionnaire were adapted from the previous study (Gumus, 2018; Lee \& Watkins 2016; Sokolova \& Kefi 2019; Yuksel, 2016) and validated by the panel. The questionnaire was randomly sent to the user account on different social media platforms.

\section{Findings and Discussion}

A total of 200 usable data were collected in the study with a response rate of 80 percent. There are 65 percent of Males respondents and 35 percent of females in the study. All the respondents are Generation Y who are active social media users.

The reliability test of the study indicates that all the variables are reliable with the value of Cronbach's alpha more than 0.67 .

\section{Multiple Linear Regression}

Table 1: Multiple Linear Regression Analysis

\begin{tabular}{cccccc}
\hline & \multicolumn{2}{c}{$\begin{array}{c}\text { Unstandardized } \\
\text { Coefficients }\end{array}$} & $\begin{array}{c}\text { Standardized } \\
\text { Coefficients }\end{array}$ & & \\
Model & B & Std. Error & Beta & t & Sig. \\
\hline (Constant) & .984 & .392 & & 2.506 & .013 \\
Source Credibility & .214 & .105 & .168 & 2.039 & .043 \\
Physical Attractiveness & .103 & .080 & .100 & 1.290 & .198 \\
Interactivity & .118 & .087 & .118 & 1.361 & .175 \\
Video Characteristic & .218 & .099 & .170 & 2.198 & .029 \\
\hline \multicolumn{6}{c}{ a. Dependent Variable: Purchase Intention } \\
b. $\mathrm{R}^{\mathrm{s}}=0.189, \mathrm{~F}=11.351$, sig level of 0.000 \\
\multicolumn{7}{c}{}
\end{tabular}

The result of the study is presented in Table 1 . the value for $\mathrm{R}$ square is 0.189 which means that the independent variables can explain $18.9 \%$ of the variation in the dependent variable. According to the ANOVA table, the F value is 11.351 and the p-value was 0.000 , which indicates a significant model.

The result of the study indicated that source credibility and video characteristic will influence the purchase intention as the p-value are 0.043 and 0.029 . Hence, hypothesizes 1 and 4 are accepted. However, P-value for physical attractiveness is 0.198 and the P-value for Interactivity is 0.175 . hence, Hypotheses 2 and 3 are rejected. Among these variables, video characteristic is the most influential factors in affecting the purchase intention of the respondents $(\mathrm{Beta}=0.218)$ compared to source credibility. 


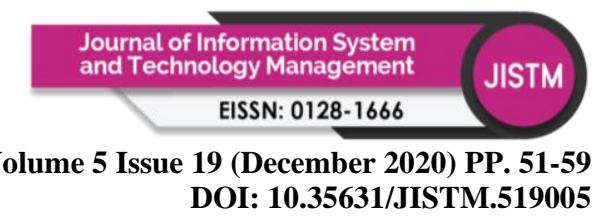

\section{Conclusion and Discussion}

\section{Relationship between Source Credibility and Purchase Intention}

This study found that the source credibility has a significant relationship with the Generation Y purchase intention as the result showed the p-value was 0.043 which is less than 0.05 .

The possible reason why the source credibility able to influence Gen Y purchase intention is that Internet celebrities are perceived as an opinion leader rather than as a spokesperson of a product. This perception is important as the consumer will normally perceive an informal source (i.e.: opinion leader) as more credible compared to a formal source (i.e: celebrities) (Schiffman and Wisenblit, 2019). In addition, most of the Internet celebrities were not restricted by their image and they are able to express their feeling better after they used a particular product and service. This will make the consumer perceived video as more credible compared to a commercial advertisement.

\section{Relationship between Physical Attractiveness and Purchase Intention}

This study found that physical attractiveness has an insignificant relationship with the Gen Y purchase intention because the result showed the p-value was 0.198 which is more than 0.05 .

According to Yuksel (2016), physical attractiveness could be in a complex and subjective definition. Physical attractiveness can come from weight, height, facial beauty, hair, body beauty, power authority, expression, or even the voice. In addition, different people perceived physical attractiveness differently. According to a critical test from Darwin (2018), males and females have a different perception of physical attractiveness. The study stated that Male perception of physical attractiveness is more focusing on Waist to Hip (WHR). Waist-to-hip ratio (WHR) is the breast size are morphological traits that are associated with female attractiveness which make a female look become sexy. On the other hand, female perceived physical attractiveness mainly on face feature, and they are not very sensitive compared to the male. However, in this study, the 65 percent of the respondents are female which is $65 \%$. This could be one of the reasons why hypothesis 2 is rejected.

\section{Relationship between Interactivity and Purchase Intention}

The study found that the interactivity has an insignificant relationship with the Gen Y purchase intention because the result showed the p-value was 0.175 which is more than 0.05 .

The Internet eased the communication and connections between peoples. On the Internet, everyone is free to comment, text, like, or share information with others. According to You, Lee \& Kim (2015), the massive usage of smart devices and social network environments had created an environment that eases for cuber-bullying through malicious comments and rumors. Malicious comments have become an unwelcome social issue now. Hence, even now interactivity between people is important but some of the consumers still perceived it as not reliable due to malicious comments and rumors exist in the market. This may become a reason that makes hypothesis 3 is rejected.

\section{Relationship between Video Characteristic and Purchase Intention}

This study found that the video characteristic has a significant relationship with the Gen Y purchase intention because the result showed the p-value was 0.029 which is less than 0.05 . 


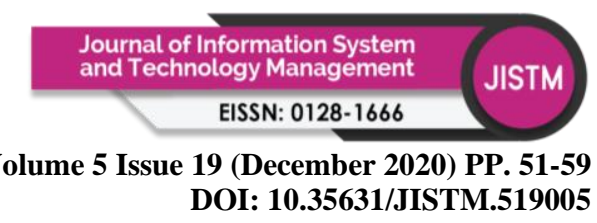

Video characteristics including style, aesthetic, and quality of the video and length of the video. According to Yuksel (2016), the quality and duration of the video, the preparation, and presentation of the content are important factors to influence the purchase decisions of consumers. A good video is able to attract people to watch and to pay attention to. This will enable the marketers to inject the brand positioning and information into the consumer's mind. Besides, according to Dobrian et.al (2013), the higher the video quality, the higher the user engagement. The higher the user engagement, the easier to influence consumer purchase intention.

\section{Conclusion}

Competition among the companies is heating up day by day and marketers are looking for alternatives ways to attract the consumer. Nowadays, more and more companies are moving from traditional media to digital media to promote their products and brand. One of the ways the marketers do is to engage the Internet celebrities in their promotion plan.

This paper helps the marketer to identify the important factor to influence the purchase intention of Generation Y Malaysia while they are using the Internet celebrities. The analysis shows that the video characteristic is an important factor that influences the purchase intention of Generation Y. Video characteristic includes the speaking style, aesthetic, quality of the video, and length of the video. To order to increase the effectiveness of the communication, the marketer can request Internet celebrities to produces more quality videos to attract the consumer. For example, the shooting, the presentation of the product, and the content of the video.

In addition, the study also found that the credibility of Internet celebrities is one of the important factors in affecting the purchase intention. The marketer needs to find Internet celebrities who perceived as credible by Generation Y (Schiffman and Wisenblit, 2019). Internet celebrities should provide reliable and persuasive information. For example, if the marketer wants to introduce the sport product, they may find the Internet celebrities who are practicing a healthy and active lifestyle.

The ever-changing market environment forced marketers to continue to adapt their strategies in order to cope with the changes. As the consumer is shifting away from traditional media, the emergence of Internet celebrities no doubts have become one of the good tools for marketers to replace and support the use of the traditional celebrities in promoting the products.

\section{References}

Albert, M. (1972). Non Verbal Communication. Cheago : Aldine.

Arnold, A. (2017). Why YouTube Stars Influence Millennials More Than Traditional Celebrities. Retrieved on 6 May 2010, from: https://www.forbes.com/sites/under30network/2017/06/20/why-youtube-starsinfluence-millennials-more-than-traditional-celebrities/\#625e65db48c6

Cai, J., \& Wohn, D. Y. (2019, January). Live streaming commerce: Uses and gratifications approach to understanding consumers' motivations. In Proceedings of the 52nd Hawaii International Conference on System Sciences.

Chang, E. C., \& Woo, T. (2019). The Influence of Internet Celebrities (Wanghongs) on Social Media Users in China. In CERC (pp. 373-379). 
Clement, J. (2019). Percentage of U.S. population who currently use any social media from 2008 to 2019. Retrieved on 6 July, from Statista: https://www.statista.com/statistics/273476/percentage-of-us-population-with-asocial-network-profile/

Darwin, C. (2018). It is certainly not true that there is in the It is certainly not true that there is in the mind of Man any universal standard of beauty with respect to the human body with respect to the human body. The Descent of Man, and Selection in Relation to Sex, 584.

Djafarova, E., \& Rushworth, C. (2017). Exploring the credibility of online celebrities' Instagram profiles in influencing the purchase decisions of young female users. Computers in Human Behavior, 68, 1-7.

Dobrian, F., Awan, A., Joseph, D., Ganjam, A., Zhan, J., Sekar, V., Stoica, I., Zhang, H. (2013). Understanding the Impact of Video Quality on User Engagement. Communications of the ACM, 56(3), 91-99.

Glucksman, M. (2017). The rise of social media influencer marketing on lifestyle branding: A case study of Lucie Fink. Elon Journal of Undergraduate Research in Communications, 8(2), 77-87.

Gutella, S. (2015). Study: $63 \%$ of young viewer most likely to try products endorsed by YouTube start. Retrieved on 26 March 2020, from: https://www.tubefilter.com/2015/03/03/defy-media-acumen-report-study/

Gumus, N. (2018). Consumers' Preseption of YouTuber: The case of Turkey. Journal of Information Technology.

Howe, N. and Strauss, W. (2000). Millennials Rising: The Next Great Generation. New York: Vintage Books.

Hsu, H. Y., Tsou, H. T. (2011). Understanding Customer Experiences in Online Blog Environments. International Journal of Information Management, 510-523.

Joseph, W. B. (1982). The credibility of physically attractive communicators; a review. Journal of Advertising.

Kaur, M (2016). Msians watch more YouTube than anyone else in the world. Retrieved on 16 May 2020, from: https://www.nst.com.my/news/2016/02/129141/msians-watchmore-

Kahle, L. R., \& Homer, P. M. (1985). Physical Attractiveness of the Celebrity Endorser: A Social Adaptation Perspective. Journal of Consumer Research, 11(4),, 954-961.

Konzack, L. (2019). Internet Phenomenon. In Advanced Methodologies and Technologies in Network Architecture, Mobile Computing, and Data Analytics (pp. 1754-1762). IGI global.

Lee, J. E., \& Watkins, B. (2016). Youtube vloggers' influence on consumer luxury brand perceptions and intentions. Journal of Business Research, 69, 5753-5760. Retrieved from Journal of Business Research, 69, 5753-5760.

McKay, B. (2018). The Future Of Media Buying: YouTube Versus Traditional TV. Retrieved on 8 May 2020, from: https://www.forbes.com/sites/forbesagencycouncil/2018/01/16/the-future-of-mediabuying-youtube-versus-traditional-tv/\#1f4997a22675

Mir and Rehman. (2013). Factors Affecting Consumer Attitudes and Intentions toward UserGenerated Product Content on YouTube. Management \& Marketing Challenges for Knowledge Society, 8(4),, 637-654. 
MCMC Internet Servery (2017). Retrieved on 8 May 2020, from: https://www.mcmc.gov.my/skmmgovmy/media/General/pdf/MCMC-Internet-UsersSurvey-2017.pdf

Ohanian, R. (1991). The impact of celebrity spokespersons' perceived image on consumers' intention to purchase. Journal of advertising Research.

Park, H. J., \& Lin, L. M. (2020). The effects of match-ups on the consumer attitudes toward internet celebrities and their live streaming contents in the context of product endorsement. Journal of Retailing and Consumer Services, 52, 101934.

Poggi, J. (2018). Nearly half of the Millennails and Gen Xers don't watch any Traditional TV: Study. Retrived on 27 May 2020, From: https://adage.com/article/media/half-youngconsumers-watching-content-traditional-tv-study/310564

Rubin, A. M., Perse, E. M., \& Powell, R. A. (1985). Loneliness, Parasocial Interaction, and Local Television News Viewing. Human Communication Research, Volume 12, Issue $2,155-180$.

Sallam, M. A. A. (2011). The impact of source credibility on Saudi consumer's attitude toward print advertisement: The moderating role of brand familiarity. International Journal of Marketing Studies, 3(4), 63.

Shareef, M. M. (2019). Social Media marketing: comparative effect of advertisement sources. Retailing and Consumer Services,46, 58-69.

Schiffman, L. G., Wisenblit, J.L. (2019). Consumer behavior. Pearson Prentice Hall. 12th ed: pp. 136-137.

Sokolova, K., \& Kefi, H. (2019). Instagram and YouTube bloggers promote it, why should I buy? How credibility and parasocial interaction influence purchase intentions. Journal of Retailing and Consumer Services, 53.

Soyacincau (2016). Malaysians are leading the world in social media and mobile. Retrieved on 18 April 2020, from: https://www.soyacincau.com/2016/05/05/malaysians-areleading-the-world-in-social-media-and-mobile/

Umeogu, B. (2012). Source credibility: a philosophical analysis. Open Journal of Philosophy, 2(02), 112.

Veirman, M. D. (2017). Marketing through Instagram influencers: the impact of number of followers and product divergence on brand attitude. International Journal of Advertising, 798-828.

Westenberg, W. (2016). The influence of You-tubers on Teenagers. Retrieved on 20 May 2020, from: https://essay.utwente.nl/71094/1/Westenberg_MA_BMS.pdf

Yuksel, H.F.(2016). Factors Affecting Purchase Intention in YouTube Videos. The Journal of the Knowledge Econmoy \& Knowledge Management, 33-47.

Yoon, K., Kim, C. H., \& Kim, M. S. (1998). A cross-cultural comparison of the effects of source credibility on attitudes and behavioral intentions. Mass Communication \& Society, 1(3/4), 153-173.

You, S., Lee, Y., \& Kim, E. (2016). Physical, social, and cyberbullying: Relationships with adolescents' psychosocial factors. Child Indicators Research, 9(3), 805-823. 